\title{
Post-Irradiation Examinations of Irradiation Creep Tested Zircaloy-2
}

\author{
Wade Karlsen ${ }^{1}$, Mykola Ivanchenko ${ }^{1}$, Ulla Ehrnstén ${ }^{1}$ and Ken R. Anderson ${ }^{2}$ \\ ${ }^{1}$ VTT Technical Research Centre, Espoo, Finland. \\ ${ }^{2}$ Bechtel Marine Propulsion Corp., Bettis Laboratory, West Mifflin, PA, USA
}

This work stems from a test program studying the in-pile creep behaviour of Zircaloy-2 materials. The work involves the post-irradiation examinations (PIE) of the Zircaloy-2 specimens creep tested under neutron irradiation at the HALDEN Test Reactor. The multiple specimens provided to VTT for PIE were creep tested to various plastic strain levels with some failing during testing. In-pile creep testing in the HALDEN Test Reactor involved final fluence levels of $\sim 3 \times 10^{20} \mathrm{n} / \mathrm{cm}^{2}$ to $5 \times 10^{20}$ $\mathrm{n} / \mathrm{cm}^{2}(>1 \mathrm{MeV})$ and temperatures of $\sim 550$ to $\sim 650^{\circ} \mathrm{F}\left(\sim 288\right.$ to $\left.\sim 343^{\circ} \mathrm{C}\right)$. The PIE of the various specimens included mainly fractography of the failed specimens using scanning electron microscopy (SEM) and detailed transmission electron microscopy (TEM) characterization.

Scanning electron microscopy fractography was carried out using a Philips/FEITM XL30 ESEM with a $\mathrm{LaB}_{6}$ electron source. The fractured specimens showed asymmetrical necking, but the fractures were ductile and similar in appearance (Fig. 1). One of the specimens showed ductile dimple features, but with dimple walls exhibiting split fracture edges, rather than single, sharp edges (e.g., the higher magnification image in Fig. 1b). Dimensional measurements showed that in all cases there was significant localization of deformation, manifested by marked necking of the specimen, while the gauge diameter even $5 \mathrm{~mm}$ away from the fracture surface was still quite close to the specified original diameter.

Transmission electron microscopy was carried out with a Philips/FEITM CM200 STEM equipped with a field emission gun (FEG) source operated at $200 \mathrm{keV}$. Images were recorded with a Gatan ${ }^{\mathrm{TM}}$ 794 retractable multi-scan camera controlled by Gatan's Digital Micrograph ${ }^{\mathrm{TM}}$ software (v. 1.82.80 Beta). Magnification calibration was verified. Foils for TEM analysis were prepared from two regions: the grip sections for irradiation defect analysis (assumed to be undeformed); and the gauge sections for characterization of deformation-related defects. Material from the grip was sliced perpendicular to the bar axis, while material in the gauge region was sliced at an angle of about 30 degrees off of perpendicular in order to produce samples suitable for $3 \mathrm{~mm}$ discs. TEM foils were electrolytically thinned to electron transparency using a twin jet-polisher. At least two adequate foils were produced from each specific location of each creep specimen, with the intent of imaging at least two areas in each of the two foils for each of the specimens. For a broad sampling of the irradiationinduced defects for analyses - and to ensure adequate statistical power to detect differences, at least 30 images were recorded for each material condition.

Bright-field TEM images of the general microstructure of irradiation-creep tested Zircaloy-2 specimens are shown in Fig. 2. Figure 3 shows higher-magnification bright-field TEM images of the primary irradiation-induced defects, <a>-type dislocation loops. The measured irradiation produced <a>-type dislocation loop populations were similar in all of the materials, with mean diameters ranging from 6 to $9 \mathrm{~nm}$, and number density from 1.8 to $2.9 \times 10^{22} / \mathrm{m}^{3}$ (dislocation density 4.5 to 7.3 $\mathrm{x} 10^{14} / \mathrm{m}^{2}$ ). Figure 3 also shows evidence of dislocation channeling. More details of the analysis will be given in the presentation. The results of this recent work presented here augment the work reported by Cockeram, et al. [1] and are directly related to and support the work reported by Kozar, et al. [2].

References:

[1] B. V. Cockeram, et al., J. of Nuclear Materials 418 (2011) p. 1.

[2] R. W. Kozar, et al., J. of Nuclear Materials 444 (2014) p. 14. 

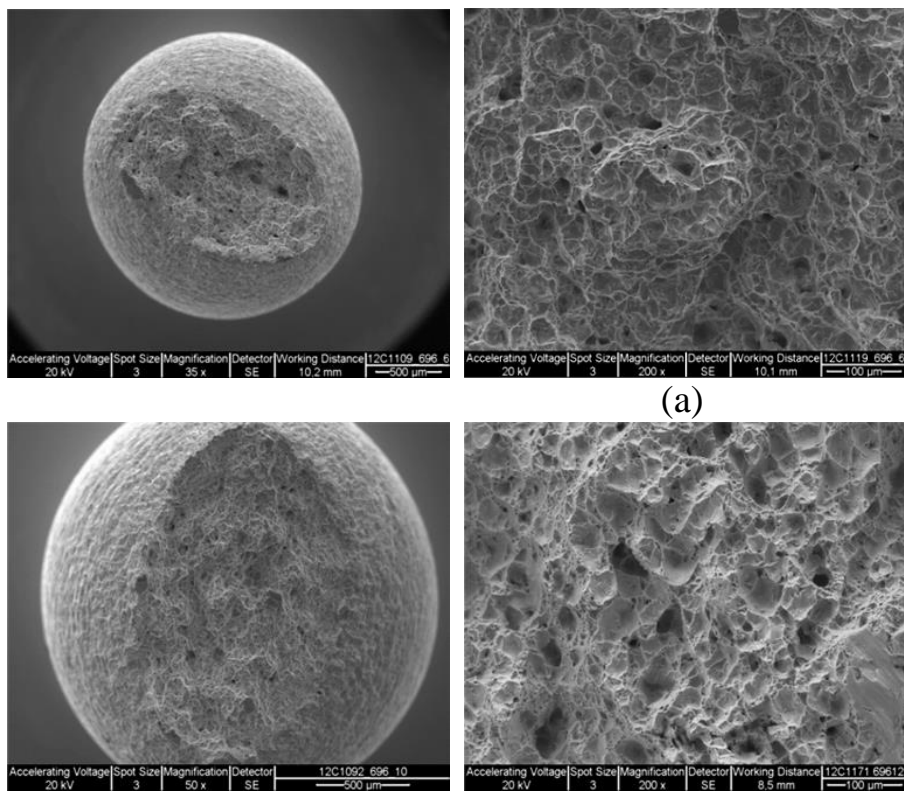

(b)

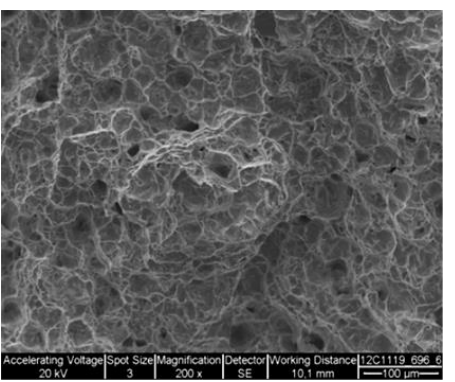

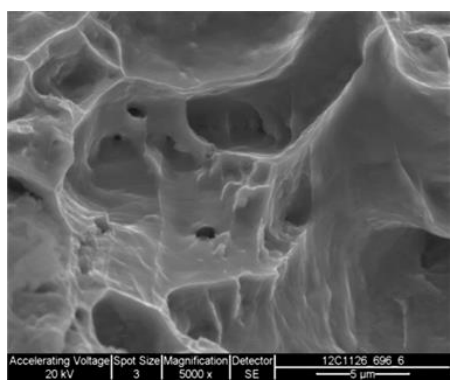

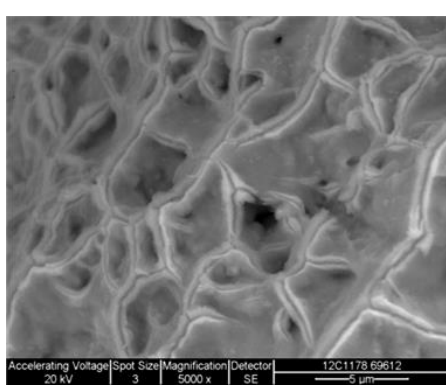

Figure 1. SEM fractography of two irradiation creep tested Zircaloy-2 specimens; (b) shows dimple walls exhibiting split fracture edges.
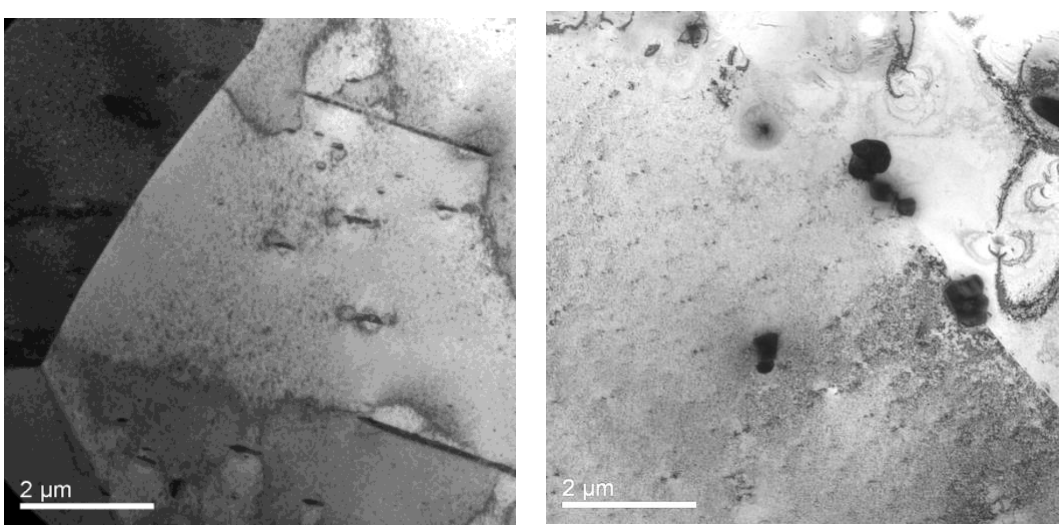

Figure 2. Low-magnification bright-field TEM images of irradiation-creep tested Zircaloy-2 showing overall microstructures, including second-phase precipitates (mainly $\mathrm{Zr}$-Fe-Cr Laves).
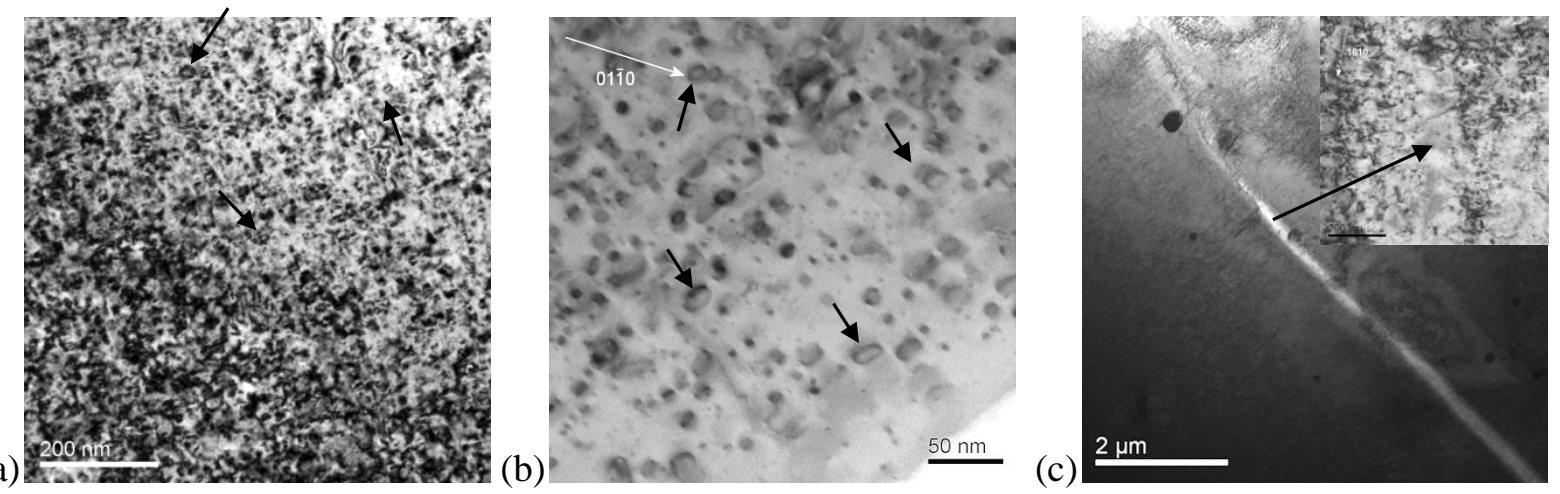

Figure 3. Higher-magnification bright-field TEM images of the primary irradiation-induced defects observed in the examined specimens: <a>-type dislocation loops formed on prism planes of the hexagonal crystal structure, (a) and (b); and an example of a clear band indicating evidence of dislocation channeling in regions close to fracture surface of the deformed gauge region (c). 